Article

\title{
Assessing the Willingness to Use Personal e-Transporters (PeTs): Results from a Cross-National Survey in Nine European Cities
}

\author{
Tim De Ceunynck ${ }^{1, *}$, Gert Jan Wijlhuizen ${ }^{2}$, Aslak Fyhri ${ }^{3}$, Regine Gerike ${ }^{4}{ }^{(}$, Dagmar Köhler ${ }^{5}$, Alice Ciccone ${ }^{3}$, \\ Atze Dijkstra ${ }^{2}$ (D), Emmanuelle Dupont ${ }^{1}$ and Mario Cools ${ }^{6,7,8}$ (D) \\ 1 Vias Institute, BE-1130 Brussels, Belgium; emmanuelle.dupont@vias.be \\ 2 SWOV Institute for Road Safety Research, 2594 The Hague, The Netherlands; \\ gert.jan.wijlhuizen@swov.nl (G.J.W.); atze.dijkstra@swov.nl (A.D.) \\ 3 TØI Institute of Transport Economics, 0349 Oslo, Norway; aslak.fyhri@toi.no (A.F.); \\ alice.ciccone@toi.no (A.C.) \\ 4 Institute of Transport Planning and Road Traffic, Technische Universität Dresden, 01069 Dresden, Germany; \\ regine.gerike@tu-dresden.de \\ 5 Polis, BE-1050 Brussels, Belgium; dkoehler@polisnetwork.eu \\ 6 Local Environment Management \& Analysis (LEMA), Urban \& Environmental Engineering (UEE), \\ University of Liège, Polytech 1, BE-4000 Liège, Belgium; mario.cools@uliege.be \\ 7 Department of Informatics, Simulation and Modeling, KU Leuven Campus Brussels, \\ BE-1000 Brussels, Belgium \\ 8 Faculty of Business Economics, Hasselt University, BE-3590 Diepenbeek, Belgium \\ * Correspondence: hello@timdeceunynck.be
}

\section{check for} updates

Citation: De Ceunynck, T.; Wijlhuizen, G.J.; Fyhri, A.; Gerike, R.; Köhler, D.; Ciccone, A.; Dijkstra, A.; Dupont, E.; Cools, M. Assessing the Willingness to Use Personal

e-Transporters (PeTs): Results from a Cross-National Survey in Nine European Cities. Sustainability 2021, 13, 3844. https://doi.org/10.3390/ su13073844

Academic Editor: Armando Cartenì

Received: 6 February 2021

Accepted: 25 March 2021

Published: 31 March 2021

Publisher's Note: MDPI stays neutral with regard to jurisdictional claims in published maps and institutional affiliations.

Copyright: (c) 2021 by the authors Licensee MDPI, Basel, Switzerland. This article is an open access article distributed under the terms and conditions of the Creative Commons Attribution (CC BY) license (https:// creativecommons.org/licenses/by/ $4.0 /)$.

\begin{abstract}
In the last few years, there has been a strong increase in the interest in and usage of so-called "Personal e-Transporters" (PeTs), also referred to as micro-mobility devices. Empirical research on the usage of PeTs as a transport mode is virtually non-existent, especially within Europe. This paper aims to fill this gap by investigating people's motivations and barriers to the use of PeTs. To this end, a behavioural survey was conducted in nine European cities. A representative sample of approximately 250 respondents per city was collected, resulting in a dataset, after data cleaning, of 2159 observations. Generally, respondents' perceptions of PeTs are not (yet) very favourable. Respondents' perceptions related to cost and safety received the lowest scores. The results from the transtheoretical model of behavioural change show that a variety of factors influence the stage of behavioural change in which the respondents can be situated. These factors include cycling norms, current walking behaviour, walking attitudes, pro-environmental orientation, gender, PeTs possession, cycling obstacles and subscription to a bicycle sharing service. An important strength of this study lies in the international nature and the size of the data collection, ensuring the reliability and transferability of the results to other cities. To the best of our knowledge, it is the first large-scale survey to investigate people's travel behaviour related to the usage of PeTs and possibly the only large-scale investigation that took place before the deployment of shared e-scooters in many European cities. Furthermore, an explicit link is made with other modes of active transport (walking and cycling).
\end{abstract}

Keywords: Personal e-Transporters; PeTs; e-scooters; active transport modes; travel behaviour; urban mobility

\section{Introduction}

Many cities today suffer from severe transport issues, including congestion, poor air quality and low liveability as a result of a strong car dependence [1]. Without substantial policy interventions, these issues are likely to increase over the next decades as a result of the world's population growth in combination with increasing urbanisation. The United Nations predicts that the share of the urban population will rise from $54 \%$ in 2014 to $66 \%$ by 2050 [2]. To ensure cities' liveability and accessibility, a significant modal shift away from car use towards more sustainable modes of transport is needed. Traditionally, public 
transit is one of these modes. An important limitation of public transport is that it is not a door-to-door solution, which means that there is a need for a trip to and from the public transport access point, also known as "access and egress trips" or first/last mile trips. These access and egress trips can greatly add time to the total travel time and can, therefore, substantially affect the attractiveness of public transport [3].

In the last few years, there is a strong increase in the interest in and usage of so-called "Personal e-Transporters" (PeTs), also referred to as micro-mobility devices or personal light electric vehicles. These PeTs are small electrically powered transport devices that allow a user to travel several kilometres, usually at speeds that are comparable to or even higher than those of bicycles. Examples of such devices are electric scooters (e-scooters), solo-wheels/mono-wheels, hoverboards, Segways, electric skateboards, etc. Note that the aforementioned examples of PeTs do not have pedals or seats. Therefore, electric bicycles or mopeds are not considered PeTs. There is already a wide variety of PeTs available, and new vehicle types and manufacturers are still entering the market. We have also seen a rapid increase in the number of cities where electric scooters are available as a shared-use service $[4,5]$.

PeTs seem to offer potential benefits that can contribute to a more sustainable transport system [6,7]. PeTs are a fast, flexible and local emission-free way of urban transport. They could potentially improve the attractiveness of public transport by offering a solution for access and egress trips [8]. Research by Smith and Schwierterman [9] suggests that shared e-scooters provide a cheaper and faster alternative when compared with more conventional modes of transport for trips between half a mile and two miles (0.8-3.2 km), particularly in urban environments. PeTs may therefore be an effective solution to urban congestion and for covering the first/last mile to other modes of transportation $[8,10]$.

At this moment, empirical research on the usage of PeTs as a transport mode is inadequate $[11,12]$. The recent surge in the usage of PeTs emphasises the need to better understand the field of PeT mobility [7]. Research about various aspects of PeTs as a transport mode is needed to understand better why people do (not) use these transport devices, how they can be integrated into the urban transport system safely and efficiently and (possibly) how their usage can be stimulated.

This paper aims to fill this research gap by investigating people's motivations and barriers to the use of PeTs. To this aim, a survey was conducted among more than 2000 respondents across nine European cities to learn about users and usages of PeTs at a very early stage. The survey was conducted in June 2018, shortly before shared dockless escooters were deployed in many European cities. None of the cities had shared dockless e-scooters in place during the time of the survey. Consequently, all participants in the survey who were experienced users of PeTs made use of, and expressed their experience with, privately-owned devices.

\section{Background}

A literature review shows a recent increase in publications related to PeTs, mostly related to shared dockless e-scooter systems. Research focusing on privately owned devices, which is the case in this study since none of the investigated cities had any shared scooter operators at the time of the study, is scarce. Most studies took place in North America.

Bai and Jiao [11] investigated the e-scooter usage patterns and compared e-scooter trips in Austin and Minneapolis (USA). The spatial analysis results show that the densest e-scooter usage happened in downtown areas and university campuses in both cities. However, the temporal characteristics of the two cities' e-scooter usage patterns turned out to be different between both cities. Furthermore, the results show that proximity to the city centre, better access to transit and greater land-use diversity positively correlated with higher e-scooter ridership in both cities. Compared to single-family residential areas, office and institutional land use were more likely to relate to higher ridership in both cities. The differences between both cities highlight the importance of local uniqueness, according to the authors. 
A similar spatial study was conducted by Caspi et al. [13]. Their study in Austin, Texas (USA) showed that people use e-scooters almost exclusively in the city centre. Commuting is not the main trip purpose, and usage of e-scooters is associated with areas with high employment rates and areas with bicycle infrastructure. E-scooters are used regardless of the affluence of the neighbourhood, although less affluent areas with high usage rates have large student populations, suggesting that students use e-scooters relatively frequently.

Almannaa et al. [14] explored the feasibility of launching an e-scooter sharing system in Saudi Arabia. The study found that the major obstacles for deploying shared e-scooters in Saudi Arabia are the lack of sufficient infrastructure, followed by weather conditions and safety. The analyses show that gender, age and using ride-hailing services (such as Uber) play an important role in respondents' willingness to ride e-scooters.

McKenzie [15] compared the spatiotemporal usage patterns of e-scooters with the station-based bike-share system in Washington D.C. (USA) and found that e-scooter trips were more similar to casual bike-share trips in terms of the time of use and were dissimilar spatially. He also pointed out that e-scooter trips mostly originated from the public/recreation area and ended at the same land use, whereas bike-share trips were predominantly home-based commutes.

A study by Fitt and Curl [16] aimed to capture early data about the use and perceptions of e-scooters by conducting a survey with 591 respondents shortly after a shared e-scooter operator arrived in New Zealand. The results suggest that younger people, men and those in full-time employment were most likely to use e-scooters. Concerns about safety, expense and suitable clothing topped the list of practical reasons for not using an e-scooter.

James et al. [17] conducted a survey of 181 e-scooter riders and non-riders, asking about their perceived safety around riders of e-scooters and experiences of sidewalks blocked by improperly parked e-scooters. Responses about safety and sidewalk blocking perceptions different strongly between riders and non-riders. Non-riders felt less safe around e-scooters than riders, and non-riders perceived a higher occurrence of sidewalks blocked by improperly parked e-scooters than riders.

Berge [18] conducted a pilot study in downtown Oslo (Norway) among 431 participants trough roadside interviews. The results suggest that e-scooters mostly replace walking and public transport. In line with the results of Fitt and Curl [16], more men than women reported having ridden an e-scooter, and most were below the age of 30. E-scooters were reported used in various contexts, but the two most common trip purposes were leisure and travel to and from work. Furthermore, the study hints at some safety issues regarding e-scooters. One in ten of the e-scooter riders have had an accident, and one in five experienced a near-miss the last time they scooted. Nevertheless, a large majority of the users feel safe in traffic. One in four pedestrians and cyclists feel unsafe when interacting with e-scooterists. Parked dockless e-scooters are considered a nuisance.

No studies were identified investigating PeTs as a broader group of mobility devices, nor any studies focusing on privately owned devices rather than publicly available devices.

\section{Methodology}

\subsection{Survey Design}

An extensive online survey was conducted in nine European cities in four countries, i.e., Ghent and Liège (Belgium), Tilburg and Groningen (The Netherlands), Trondheim and Bergen (Norway) and Düsseldorf, Dortmund and Berlin (Germany). A representative sample of approximately 250 respondents per city was targeted. Representativeness was monitored using soft quota based on city-level population data of gender and age (three categories). Only respondents aged 18 or older were included. The data collection took place from 15 to 27 June 2018. It is important to emphasise the timing of the data collection, which took place shortly before shared-use electric scooters started to be introduced in a large number of European cities (which started around summer/autumn 2018). None of the investigated cities had shared e-scooter services available at the time of the data collection. 
The full English master version of the questionnaire can be obtained from the authors on request. The structure of the questionnaire is briefly introduced here. The questionnaire was translated to German (Düsseldorf, Dortmund and Berlin), Norwegian (Trondheim and Bergen), French (Liège), "Flemish" Dutch (Ghent) and "Netherlands" Dutch (Tilburg and Groningen).

The questionnaire started with a general introduction and several questions to screen whether the respondent met the inclusion criteria. These questions were related to the country and postal code, birth year and whether they experience physical difficulties to walk or cycle. Respondents who indicated that walking and cycling are physically impossible for them were screened out.

In the next section, various socio-demographic variables were collected. These included gender, education level, living situation, vehicle ownership, license possession, possession of a season ticket for public transport, subscription to a bike or car-sharing system and whether they could easily park a bicycle at home. Then, respondents were asked how frequently they use various transport modes.

Before asking the questions related to PeTs, respondents received explanations on what PeTs are, including example pictures. First, the possession rate of such devices was queried. Then, respondents' perceptions of PeTs were measured on six items (fast, convenient, fashionable/cool, safe, cheap and pleasant/fun). Consequently, respondents were asked for the frequency of usage of PeTs in the last 12 months.

Finally, a question was asked to measure respondents' stage of behavioural change towards using PeTs. The different stages are based on the Transtheoretical Model of Behavioural Change $[19,20]$. We distinguish the following stages.

- Pre-contemplation stage: The participant indicates that $\mathrm{s} /$ he has never thought about travelling by PeT.

- Contemplation with preparation stage: The participant indicates that $\mathrm{s} /$ he has never travelled by PeT, but sometimes considers it.

- Contemplation without preparation stage: The participant indicates that s/he sometimes travels by PeT but is not really considering to do it more regularly. Note that this stage is not part of the initial framework by Bamberg [19]. However, the authors felt that respondents should be able to indicate that they are already using PeTs sometimes but are not intending to increase usage.

- Preparation stage: The participant indicates that $\mathrm{s} /$ he sometimes travels by PeT and is seriously thinking about doing so more regularly.

- Action stage: The participant indicates that $\mathrm{s} /$ he recently started to travel more frequently by PeT and is planning to keep on doing so in the future.

- Maintenance: The participant indicates that $\mathrm{s} /$ he has been travelling more frequently by PeT for some time now.

Several blocks of questions dealt with the psychological determinants of transport mode choice related to walking and cycling. Due to the anticipated high level of respondents without any experience with Personal e-Transporters, extensive questions related to psychological determinants of PeT usage were considered infeasible. Detailed analyses of the determinants of walking and cycling are beyond the scope of this paper. However, these components were inserted in the stage model about PeT usage to see if there are relations between people's behavioural components related to walking/cycling and PeT usage.

The order of the blocks was randomised to prevent possible biases due to order effects. All questions were asked on a seven-point Likert scale. Walking and cycling (treated as two separate transport modes) attitudes were questioned in five items (fast, convenient, safe, good and pleasant). Norms were interviewed using three questions, each of which related to one of the different types of norms identified in our theoretical model (subjective norm, descriptive norm and personal norm). Perceived behavioural control was assessed for controllability (three items for cycling and two for walking) and self-efficacy (three items for each mode). Intentions were measured using three items for each mode. Behaviour was measured by asking respondents to fill in the number of trips by bike/foot they 
made in the past 30 days for three types of activities. Respondents were also asked how important/problematic five obstacles (physical effort, time, cost, physical environment (climate, hilliness, etc.) and traffic safety) were for them to walk/cycle more frequently.

Habit is measured using three questions, asking to what extent several types of trips are considered an "ingrained routine". People's environmental consciousness is measured using six questions from The New Ecological Paradigm Scale (NEPS) [21] that appeared to be relevant in a previous study on road pricing by Cools et al. [22].

\subsection{Data Preparation}

The data preparation stage concerned: (i) labelling and formatting of variables; (ii) advanced data cleaning; and (iii) weighting of the observations. In terms of data cleaning, from an original 2308 observations, 2159 observations were retained for further analysis. Reasons for deletion were: (i) respondents indicating that they did not complete the question in a correct way; (ii) straight-liners; and (iii) respondents with abnormal responses (e.g., unrealistic age or too high vehicle possessions).

In terms of weighting, the joint age (18-34, 35-54 or $\geq 55)$ / gender distribution was used, using the most recently available (complete) joint distribution per city. The population data used to determine the weights were retrieved from Eurostat. The minimum weight equalled 0.59, the maximum 3.05. These extremes are in line with typical cut-off values used in weights for travel surveys, such as OVG, which adopts cut-off values of 0.35 and 3.00 [23]. By definition, the average weight per city equalled 1. An overview of the weights is provided in Table 1.

Table 1. Sample weights per city.

\begin{tabular}{|c|c|c|c|c|c|c|c|c|}
\hline \multicolumn{3}{|c|}{ Ghent } & \multicolumn{3}{|c|}{ Liège } & \multicolumn{3}{|c|}{ Tilburg } \\
\hline & Male & Female & & Male & Female & & Male & Female \\
\hline $18-34$ & 1.79 & 0.99 & $18-34$ & 1.29 & 1.01 & $18-34$ & 1.56 & 0.68 \\
\hline $35-54$ & 1.21 & 0.71 & $35-54$ & 1.17 & 0.85 & $35-54$ & 1.38 & 0.89 \\
\hline $55+$ & 0.70 & 1.19 & $55+$ & 0.77 & 1.09 & $55+$ & 0.80 & 1.19 \\
\hline \multicolumn{3}{|c|}{ Groningen } & \multicolumn{3}{|c|}{ Dusseldorf } & \multicolumn{3}{|c|}{ Dortmund } \\
\hline & Male & Female & & Male & Female & & Male & Female \\
\hline $18-34$ & 2.42 & 0.76 & $18-34$ & 0.92 & 1.02 & $18-34$ & 1.10 & 0.75 \\
\hline $35-54$ & 0.79 & 1.00 & $35-54$ & 1.25 & 0.869 & $35-54$ & 1.15 & 0.88 \\
\hline $55+$ & 0.67 & 1.34 & $55+$ & 0.86 & 1.135 & $55+$ & 0.93 & 1.28 \\
\hline \multicolumn{3}{|c|}{ Berlin } & \multicolumn{3}{|c|}{ Bergen } & \multicolumn{3}{|c|}{ Trondheim } \\
\hline & Male & Female & & Male & Female & & Male & Female \\
\hline $18-34$ & 0.91 & 0.92 & $18-34$ & 3.05 & 0.59 & $18-34$ & 1.96 & 0.61 \\
\hline $35-54$ & 1.18 & 0.92 & $35-54$ & 1.00 & 1.04 & $35-54$ & 0.97 & 1.10 \\
\hline $55+$ & 0.97 & 1.12 & $55+$ & 0.59 & 2.22 & $55+$ & 0.61 & 2.45 \\
\hline
\end{tabular}

\subsection{Data Analysis}

To investigate the role of psychological determinants and socio-demographic factors on travel mode choice, a stage of behaviour change model was constructed using a multinomial logit (MNL) model. We opted for an MNL model as the proportional odds assumption of the ordered logit was violated $\left(\mathrm{Chi}^{2}\right.$-value $=70.7$, degrees of freedom $=16$, $p$-value < 0.01). An MNL model is a model that is used to predict the probabilities of the different possible outcomes of a categorically distributed dependent variable, given a set of independent variables. Let $Y$ (the stage of behavioural change) be the response variable, $y_{i}=\left(y_{i 1}, y_{i 2}, y_{i 3}\right)^{\mathrm{T}}$, that has a multinomial distribution $\pi_{i}=\left(\pi_{i 1}, \pi_{i 2}, \pi_{i 3}\right)^{\mathrm{T}}$, and let $X$ be a set of explanatory variables (discrete and/or continuous). Taking $j^{*}$ as the baseline category (i.e., the pre-contemplation stage in this study), the model can be represented by the following equation: 


$$
\log \left(\frac{\pi_{i j}}{\pi_{i j^{*}}}\right)=x_{i}^{T} \beta_{j}, j \neq j^{*}
$$

For the stage model, all variables are transformed to binary or continuous for ease of interpretation. For binary variables, the estimate values of the model indicate the odds of being in that stage compared to the odds of being in the first (pre-contemplation) stage for respondents for which the value of the binary indicator is 1 compared to those for which it is 0 . For continuous variables, it shows the increase in the odds of being in that stage compared to the odds of being in the first (pre-contemplation) stage for a one-unit increase in the value of the continuous variable.

To assess the significance of the independent variables, a type III analysis of the effects is made. In contrast to the individual parameters, the overall type III analysis pinpoints which variables significantly explain respondents' stage of behavioural change.

Variance Inflation Factors (VIFs) are used to check the model for multicollinearity. Multicollinearity is a phenomenon in which an independent variable can be linearly predicted from the other independent variables in the model with a substantial degree of accuracy. In this situation, the coefficient estimates of the regression model may change erratically in response to small changes in the model or the data, and therefore compromises the reliability of the model. Low VIFs indicate that the model does not suffer substantially from multicollinearity [24]. All VIFs in the presented stage model were below 4, which means that the model does not suffer from issues with multicollinearity.

For the model of increased PeT usage, a simplified stage model was fit. This was done to improve the robustness of the model, since the number of respondents in the higher stages of behaviour change were relatively low. The original six stages were merged into three stages for building the model. The pre-contemplation stage remained unchanged, since it is by far the largest group ( $73.3 \%$ of respondents) and has few similarities with the other stages. The "contemplation, no preparation" stage was merged with the "contemplation" stage. Finally, the highest three stages were grouped together in a group that is referred to as the "initiative" stage. The percentages of respondents in each of the stages is shown in Table 2.

Table 2. Percentage of respondents in the different stages (original and regrouped).

\begin{tabular}{|c|c|c|c|}
\hline $\begin{array}{l}\text { Stage in the Cycle of } \\
\text { Change (Original) }\end{array}$ & $\%$ & $\begin{array}{l}\text { Stage in the Cycle of } \\
\text { Change (Regrouped) }\end{array}$ & $\%$ \\
\hline Pre-contemplation & $73.4 \%$ & Pre-contemplation & $73.4 \%$ \\
\hline Contemplation & $19.1 \%$ & \multirow{2}{*}{ Contemplation } & \multirow{2}{*}{$22.1 \%$} \\
\hline Contemplation, no preparation & $3.0 \%$ & & \\
\hline Preparation & $2.3 \%$ & \multirow{3}{*}{ Initiative } & \multirow{3}{*}{$4.5 \%$} \\
\hline Action & $0.8 \%$ & & \\
\hline Maintenance & $1.4 \%$ & & \\
\hline
\end{tabular}

\section{Results}

\subsection{Descriptive Statistics}

Table 3 shows the characteristics of the sample. The largest group of respondents are living alone, followed by living with a partner but without children. It can be observed that bicycle possession per household is high (1.45 regular bicycles and 0.16 e-bikes on average). The mean passenger car possession is slightly below one car per household. Most respondents (more than $80 \%$ ) possess a driving license. Almost half of the respondents have a season ticket for public transport, but the number of respondents subscribed to car-sharing (8\%) and bicycle sharing (5\%) systems is relatively low. The vast majority of the sample is physically fit and can walk and cycle without any difficulties. 
Table 3. Descriptive statistics of the full sample of the survey.

\begin{tabular}{|c|c|c|}
\hline Variable & Categories & Full Sample \\
\hline \multirow{3}{*}{ Age } & $18-34$ & $32.7 \%$ \\
\hline & $35-54$ & $33.3 \%$ \\
\hline & $55+$ & $34.1 \%$ \\
\hline \multirow{2}{*}{ Gender } & Female & $50.9 \%$ \\
\hline & Male & $49.1 \%$ \\
\hline \multirow{4}{*}{ Degree } & None/primary education & $3.7 \%$ \\
\hline & Secondary education & $45.7 \%$ \\
\hline & Bachelor's degree or similar & $32.5 \%$ \\
\hline & Master's degree or higher & $18.1 \%$ \\
\hline \multirow{6}{*}{ Living situation } & I live alone & $32.2 \%$ \\
\hline & I live without a partner. with children & $5.5 \%$ \\
\hline & I live with my parents & $8.1 \%$ \\
\hline & I live with a partner. without children & $27.8 \%$ \\
\hline & I live with a partner and children & $19.9 \%$ \\
\hline & Other living situation & $6.5 \%$ \\
\hline \multirow{5}{*}{$\begin{array}{l}\text { Vehicle ownership per } \\
\text { household (mean number of } \\
\text { vehicles in your household that } \\
\text { are available for you to use) }\end{array}$} & Bicycle & 1.45 \\
\hline & Electric bicycle & 0.16 \\
\hline & Motorised two-wheeler & 0.13 \\
\hline & Passenger car & 0.97 \\
\hline & $\begin{array}{c}\text { Personal e-Transporters (e.g., electric scooter, } \\
\text { monowheel, Segway, hoverboard,... ) }\end{array}$ & 0.16 \\
\hline \multirow{2}{*}{$\begin{array}{l}\text { Season ticket for } \\
\text { public transport }\end{array}$} & Yes & $44.3 \%$ \\
\hline & No & $55.7 \%$ \\
\hline \multirow{2}{*}{ Car driving license } & Yes & $82.4 \%$ \\
\hline & No & $17.6 \%$ \\
\hline \multirow{3}{*}{$\begin{array}{l}\text { Subscription to a } \\
\text { car-sharing system }\end{array}$} & Yes & $7.8 \%$ \\
\hline & No & $86.6 \%$ \\
\hline & I do not know what this is & $5.6 \%$ \\
\hline \multirow{3}{*}{$\begin{array}{l}\text { Subscription to a bicycle } \\
\text { sharing system }\end{array}$} & Yes & $4.7 \%$ \\
\hline & No & $87.0 \%$ \\
\hline & I do not know what this is & $8.3 \%$ \\
\hline \multirow{2}{*}{$\begin{array}{l}\text { Can you park your bicycle } \\
\text { easily at home? }\end{array}$} & Yes & $89.0 \%$ \\
\hline & No & $11.0 \%$ \\
\hline \multirow{3}{*}{$\begin{array}{l}\text { Do you know how to ride } \\
\text { a bicycle? }\end{array}$} & Yes & $95.5 \%$ \\
\hline & No & $4.0 \%$ \\
\hline & Prefer not to answer & $0.5 \%$ \\
\hline \multirow{4}{*}{$\begin{array}{l}\text { To what extent do you } \\
\text { experience difficulties in } \\
\text { walking (for at least } 10 \text { minutes) } \\
\text { because of physical reasons? }\end{array}$} & Is no problem for me & $89.8 \%$ \\
\hline & Is possible, but with difficulty & $7.8 \%$ \\
\hline & Is only possible with special assistance & $2.0 \%$ \\
\hline & Is impossible & $0.5 \%$ \\
\hline
\end{tabular}


Table 3. Cont.

\begin{tabular}{ccc}
\hline Variable & Categories & Full Sample \\
\hline & Is no problem for me & $80.7 \%$ \\
\cline { 2 - 3 } $\begin{array}{c}\text { To what extent do you } \\
\text { experience difficulties in cycling } \\
\text { because of physical reasons? }\end{array}$ & Is possible, but with difficulty & $11.6 \%$ \\
\cline { 2 - 3 } & Is only possible with special assistance & $2.3 \%$ \\
\cline { 2 - 3 } & Is impossible & $5.5 \%$ \\
\hline
\end{tabular}

\subsection{Current Usage of PeTs}

Figure 1 shows the current usage of PeTs in the nine investigated cities. Note that the y-axis starts at $50 \%$ instead of $0 \%$ to show small percentages more clearly. The current usage is highest in the three German cities and in Groningen, where approximately $10 \%$ of respondents indicate that they use PeTs at least every month (one to a few days per month or more frequently). The usage is lowest in the Norwegian cities, where monthly usage is $2 \%$ or lower.

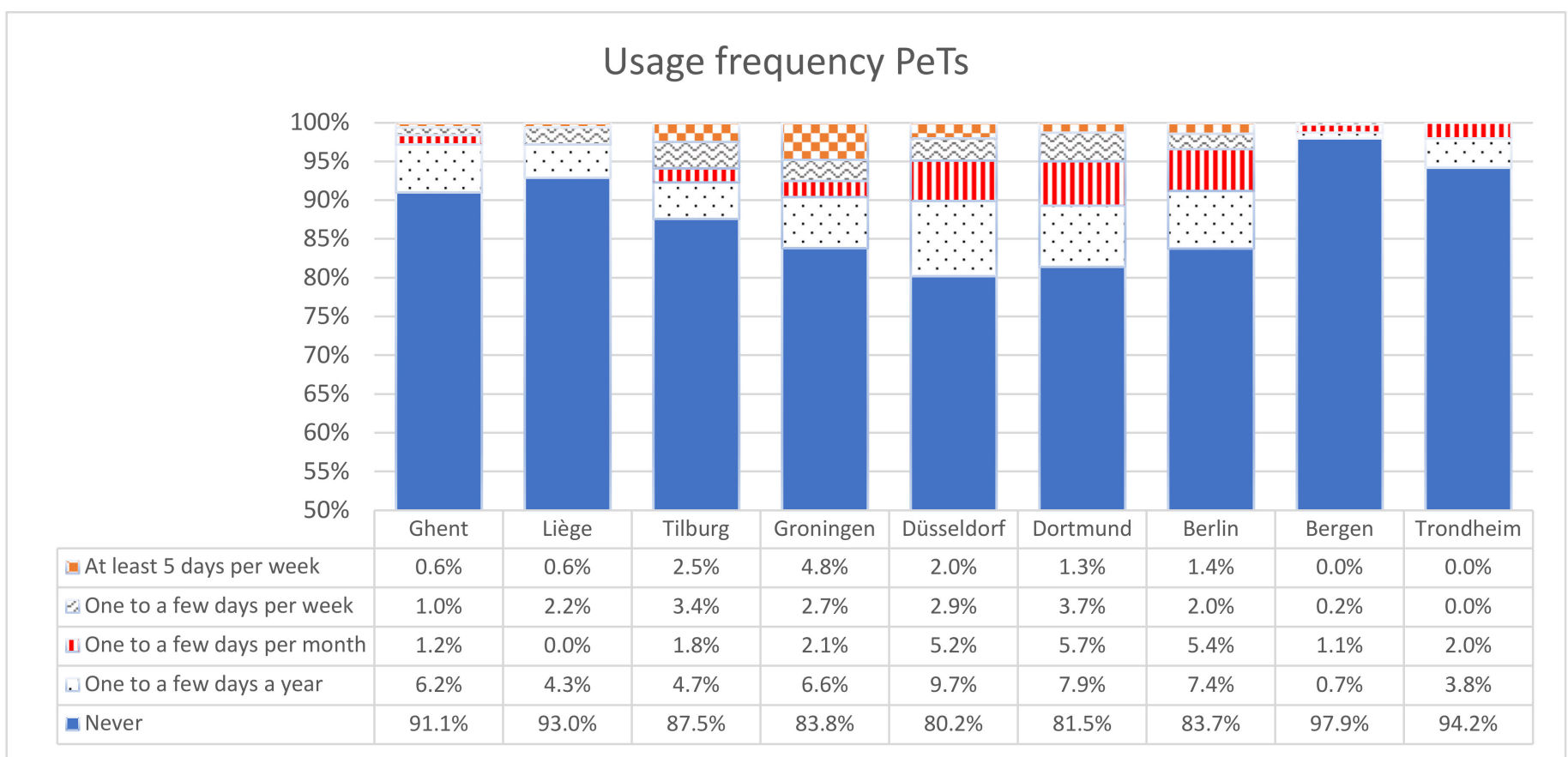

Figure 1. Usage of PeTs per city (in percentage of respondents per category).

\subsection{Perceptions of PeTs}

Figure 2 presents respondents' perceptions related to using PeTs for their daily travel on a seven-point Likert scale. Since 4 is the neutral value in the seven-point scale, we can see that, on average, respondents' attitudes towards PeTs are not yet very favourable. Generally, respondents' perceptions related to cost and safety received the lowest scores. Statistically significant differences between the cities are observed. The most favourable perceptions are reported in the German cities, especially in Dortmund. Perhaps most noteworthy are their more favourable perceptions related to cost and safety. The least favourable perceptions are reported in Bergen and Trondheim, followed by Tilburg. 


\section{Perceptions of PeTs}

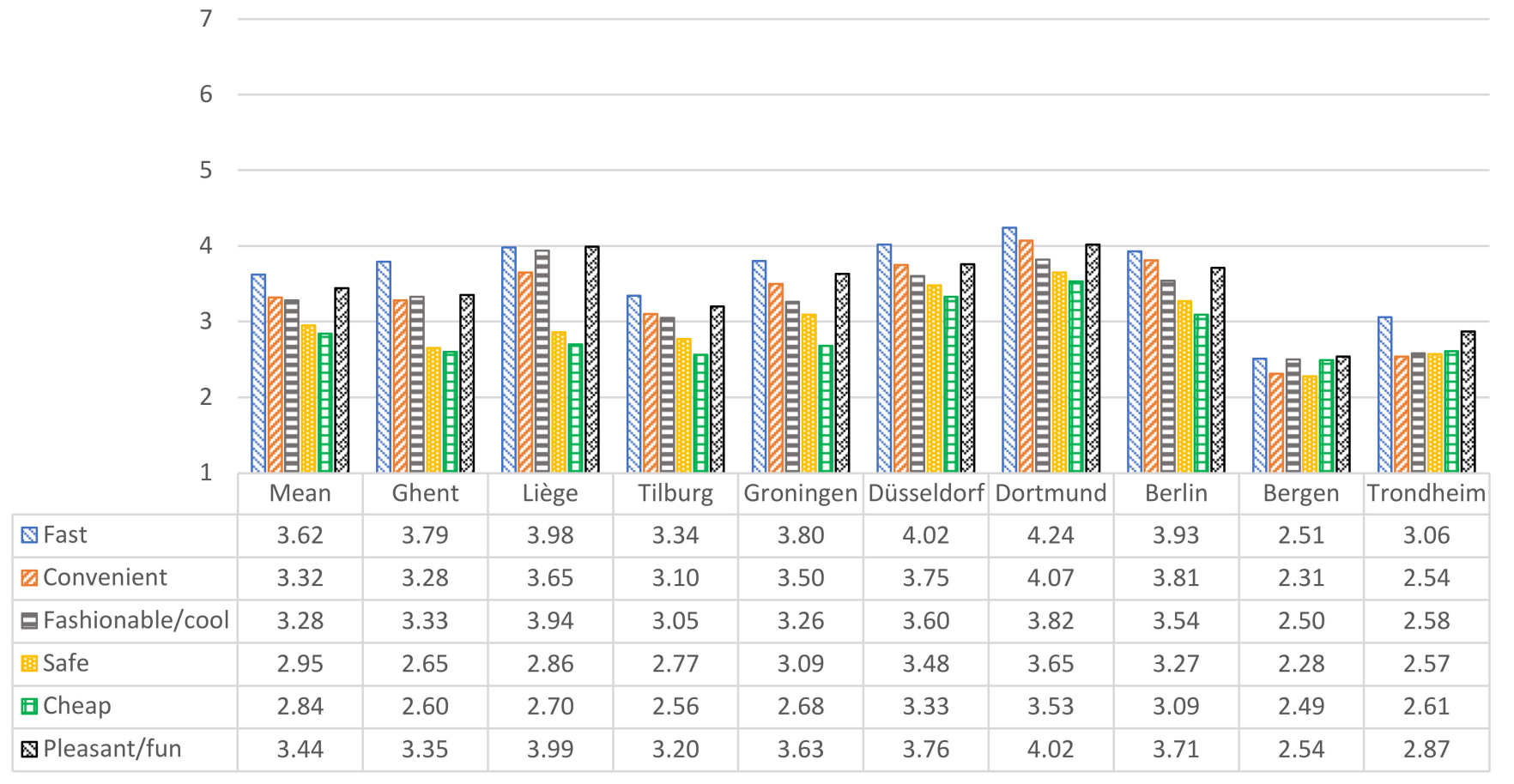

Figure 2. Perceptions of PeTs per city (on a seven-point Likert scale).

\subsection{Stage Model}

Recall that the stage of change model regarding PeTs usage was modelled using an MNL model. The overall type III level of significance tests of the model are presented in Table 4. For completeness, variables that were not retained in the final model due to lack of improvement to the model fit are mentioned in the table but indicated with "-". Note that the pre-contemplation stage was used as the reference stage. Table 5 shows the parameter estimates for the variables included in the final model.

One can observe that participants with stronger cycling norms have a significantly higher probability of being in the higher stages of behaviour change. Participants who indicate that they walk more frequently are significantly more likely to be in the higher stages. Participants with higher walking attitudes, on the other hand, are significantly less likely to be in the higher stages. Participants with a higher NEPS are significantly less likely to be in the highest (initiative) stage. Women are less likely to be in the higher stages of the model than men. Unsurprisingly, respondents with a higher possession of PeTs are significantly more likely to be in a higher stage. Respondents with higher perceived cycling obstacles are significantly more likely to be in the contemplation stage. Finally, respondents with a subscription to a bike-sharing service are less likely to be in the highest (initiative) stage. City is included as a control variable. The variable is statistically significant, suggesting that unobserved differences between the included cities explain to some extent the stage of behavioural change that their inhabitants are in. 
Table 4. Type III significance tests for stage model PeTs.

\begin{tabular}{|c|c|c|c|}
\hline \multirow{2}{*}{ Variable } & \multirow{2}{*}{ DF } & \multicolumn{2}{|c|}{ Stage Model PeTs } \\
\hline & & $\mathrm{Chi}^{2}$-Value & $p$-Value \\
\hline Cycling Behaviour & 2 & - & - \\
\hline Cycling Intention & 2 & - & - \\
\hline Cycling Attitude & 2 & - & - \\
\hline Cycling Norms & 2 & 40.6 & $<0.001$ \\
\hline Cycling Perceived Behavioural Control & 2 & - & - \\
\hline Walking Behaviour & 2 & 20.6 & $<0.001$ \\
\hline Walking Intention & 2 & - & - \\
\hline Walking Attitude & 2 & 20.5 & $<0.001$ \\
\hline Walking Norms & 2 & - & - \\
\hline Walking Perceived Behavioural Control & 2 & - & - \\
\hline Transport Mode Habit & 2 & - & - \\
\hline New Ecological Paradigm Scale & 2 & 8.4 & 0.015 \\
\hline Age & 2 & - & - \\
\hline Gender & 2 & 36.1 & $<0.001$ \\
\hline Bicycle Possession & 2 & - & - \\
\hline Car Possession & 2 & - & - \\
\hline Personal e-Transporter Possession & 2 & 67.2 & $<0.001$ \\
\hline Cycling Obstacles & 2 & 15.7 & $<0.001$ \\
\hline Walking Obstacles & 2 & - & - \\
\hline Subscription to Car Sharing Service & 2 & - & - \\
\hline Subscription to Bike Sharing Service & 2 & 6.9 & 0.032 \\
\hline Driving License Possession & 2 & - & - \\
\hline Season Ticket Public Transport & 2 & - & - \\
\hline Living situation-with partner & 2 & - & - \\
\hline Living situation-with child & 2 & - & - \\
\hline Degree & 2 & - & - \\
\hline City & 16 & 70.7 & $<0.001$ \\
\hline
\end{tabular}

AIC: 2492.86

Nagelkerke $R^{2}$ : 0.24

$n=2038$

Table 5. Parameter estimates stage model PeTs.

\begin{tabular}{ccccc}
\hline \multirow{2}{*}{ Parameter } & \multicolumn{2}{c}{ Contemplation Stage } & \multicolumn{2}{c}{ Initiative Stage } \\
\cline { 2 - 5 } & Est. & S.E. & Est. & S.E. \\
\hline Intercept & -1.73 & 0.53 & -1.40 & 1.20 \\
\hline Cycling Norms & 0.25 & 0.04 & 0.39 & 0.11 \\
\hline Walking Behaviour & 0.02 & 0.01 & 0.06 & 0.02 \\
\hline Walking Attitude & -0.16 & 0.04 & -0.33 & 0.10 \\
\hline New Ecological Paradigm Scale & 0.04 & 0.05 & -0.33 & 0.13 \\
\hline Gender (Female) & -0.57 & 0.12 & -1.20 & 0.29 \\
\hline
\end{tabular}


Table 5. Cont.

\begin{tabular}{ccccc}
\hline \multirow{2}{*}{ Parameter } & \multicolumn{2}{c}{ Contemplation Stage } & \multicolumn{2}{c}{ Initiative Stage } \\
\cline { 2 - 5 } & Est. & S.E. & Est. & S.E. \\
\hline Personal e-Transporter Possession & 0.76 & 0.23 & 2.49 & 0.30 \\
\hline Cycling Obstacles & 0.17 & 0.04 & 0.12 & 0.10 \\
\hline Subscription to Bike Sharing Service & -0.11 & 0.17 & -0.80 & 0.30 \\
\hline City-Ghent & -1.10 & 0.27 & 0.68 & 0.73 \\
\hline City-Liège & 0.13 & 0.24 & 0.75 & 0.79 \\
\hline City-Tilburg & -0.96 & 0.27 & 1.17 & 0.70 \\
\hline City-Groningen & -0.53 & 0.25 & 0.69 & 0.72 \\
\hline City-Düsseldorf & 0.22 & 0.22 & 1.10 & 0.71 \\
\hline City-Dortmund & 0.31 & 0.23 & 1.75 & 0.68 \\
\hline City-Berlin & 0.31 & 0.22 & 1.03 & 0.72 \\
\hline City-Bergen & -0.01 & 0.23 & -0.13 & 0.99 \\
\hline
\end{tabular}

\section{Discussion and Conclusions}

\subsection{Summary of Findings}

The PeTs usage at the time of the data collection (June 2018) was highest in the German cities Düsseldorf, Dortmund and Berlin and the Dutch city Groningen. Surprisingly, most types of PeTs (including e-scooters) were not officially allowed on the public roads in any of these cities. In Germany, PeTs have only been allowed on public roads since the introduction of the Elektrokleinstfahrzeuge-verordnung in June 2019. Their design-related maximum speed is $20 \mathrm{~km} / \mathrm{h}$. In The Netherlands, to date, most types of PeTs are still illegal for use on public roads. In Belgium and Norway, however, a legal framework has been in place for using PeTs as a transport mode for a longer time. In the Norwegian legislation, PeTs are defined as bicycles and are allowed on public roads (with a maximum speed of $20 \mathrm{~km} / \mathrm{h}$ ). They are also permitted on sidewalks when pedestrian volumes are low and the rider does not present a hazard or impede walking; passing pedestrians must be done at a safe distance and at approximately walking speed. In the Belgian traffic code, PeTs fall under a specific category referred to as "voortbewegingstoestellen" (loosely translated as "locomotion devices") in Dutch. At the time of the survey, there was a maximum speed of $18 \mathrm{~km} / \mathrm{h}$ for these devices, but this limit was raised to $25 \mathrm{~km} / \mathrm{h}$ in May 2019.

Generally, respondents' perceptions of PeTs are not (yet) very favourable. Respondents' perceptions related to cost and safety received the lowest scores. This finding is in line with those in [16]. Significant differences between the cities can be observed. Generally, the most favourable perceptions are reported in the German cities, especially in Dortmund. The least favourable perceptions are reported in the Norwegian cities Bergen and Trondheim.

The results from the transtheoretical model of behavioural change show that a variety of factors influence the stage of change behavioural change in which the respondents can be situated. Respondents with more positive cycling norms are more likely to be in the higher stages of behavioural change. This indicates that people who believe that others think cycling is a good thing to do are more likely to be in the higher stages of the model. The interpretation of this link is unclear but may relate to some extent to a broader concept of norms related to active transport modes in general.

Respondents who walk more often are more likely to be in the higher stages as well, but respondents with more favourable walking attitudes have a lower probability. This could suggest that, on the one hand, people who walk more often generally have more short trips in their daily schedules that could be replaced by using a PeT. On the other hand, when they like walking (i.e., have more favourable walking attitudes), they are more likely to stick to walking as a transport mode rather than switching to using a PeT. In other 
words, it might indicate that PeTs are more appealing to people who walk regularly but see walking as a necessity rather than an enjoyable activity.

Stronger transport mode habits are related to a lower chance of being in the higher stages. It is well-known that transport mode habits can be strong and difficult to break [25] Therefore, people with stronger habits of using specific (non-PeT) transport modes are less likely to get into higher stages of the model than people who generally have less strong transport mode habits (possibly because they have more fluctuating trip schedules, chose to make their mode choice decisions in a more considered way and/or have a tendency to shift more between transport modes).

Respondents with a higher NEPS are significantly less likely to be in the highest (initiative) stage. This suggests that respondents with a more pro-environmental orientation are less likely to use PeTs. A possible explanation could be that respondents with higher NEPS believe PeTs are not sufficiently environmentally friendly, and therefore favour various other modes of transportation, such as walking, cycling and public transportation, that have a lower $\mathrm{CO}_{2}$ footprint per passenger mile [8].

Respondents who indicate stronger cycling obstacles have a higher probability of being in the contemplation stage of using PeTs. This indicates that people who believe that obstacles are hindering them from cycling more frequently are more likely to contemplate using PeTs as a transport mode. In other words, PeTs are by some considered a good alternative to cycling in the presence of obstacles that hinder cycling (such as perceived physical effort, climate and hilliness, etc.).

Women are generally less likely to be in the higher stages than men. This finding is in line with existing research $[14,16,18,26]$. This might be related to the perceived unsafety of Personal e-Transporters. Generally, women are less risk-taking than men, as well as make less use of more risky transport modes such as motorcycles [27-29]. Should this be the case, it confirms the importance of improving the subjective and probably also the objective safety of PeTs to increase their usage.

Respondents with a subscription to a bike-sharing service have a lower probability of being in the highest (initiative) stage of behavioural change. This suggests that there is some competition between bike-sharing services and PeTs. This is related to the fact that both transport modes have a strong focus on trips within the city or access/egress trips to/from public transport. However, it is relevant to note from a study by McKenzie [15] that shared e-scooter services are used in substantially different ways than bike-share services. The difference in results might be caused by the fact that the PeTs in our study are not shared devices but privately owned devices.

\subsection{Policy Implications}

Some concerns are arising around the safety of PeTs in the general public. Research around the safety of PeTs is scarce, and more research is needed to better understand the contributing factors of crashes involving PeTs and what measures can be taken to mitigate the issues [30-32]. A sufficiently high level of safety is a necessary prerequisite for PeTs to be considered a sustainable means of transport. This finding is in line with Almannaa et al. [14], who identified lack of safety as a major obstacle for deploying e-scooter sharing systems in Saudi Arabia, and with Fitt and Curl [16], who identified safety as one of the main concerns for using e-scooters. The safety of PeTs can be improved both by stricter vehicle design standards for safe operation on public roads as well as through a clear regulatory framework and rules of conduct. Another important element will be to improve the infrastructure for usage by PeTs, as well as to determine the most desirable places in the public space to make use of PeTs. The presence of bicycle infrastructure correlated with the usage of e-scooters in earlier research [13]. The rise of PeTs can add to the growing variation in the types of vehicles that make use of cycling infrastructure; the infrastructure will need to be designed and updated to allow for safe usage by these diverse users [33]. PeTs can also put pressure and safety hazards on pedestrian areas and sidewalks [34]. Finally, the perceived unsafety of PeTs might also partly be affected by a lack of experience 
with these devices. James et al. [17] found that non-users of dockless e-scooters feel less safe in traffic around e-scooters than users.

Since respondents do not at all consider PeTs a cheap means of transport, lowering the costs of PeTs could increase their usage. It is, however, questionable whether one should prioritise providing (financial) incentives for PeTs given the concerns about the safety of these devices. In addition, they may replace more active transport modes, such as walking and cycling. This would be an undesirable effect since active transport modes have proven health benefits resulting from exercising physical activity [35]. Some exploratory research suggests that trips undertaken by shared e-scooters mainly replace walking or public transport trips [18]. Krier et al. [36] also showed that, in Paris, only $8 \%$ of e-scooter trips replaced car trips. Some other studies, however, reported a substantial share of the trips replaced a car trip. Thirty-four percent of e-scooter riders who are Portland residents and $48 \%$ of Portland (USA) visitors stated that their e-scooter trip had replaced a trip by car (personal car, taxi, Uber or Lyft) [37]. James et al. [17] found similar results, with 39\% of investigated e-scooter trips in Rosslyn, Virginia (USA) replacing trips that otherwise would have been taken by taxi or a ride-hailing service, although a large part of the remainder of the trips replaced trips otherwise taken by foot $(33 \%)$ or by bicycle $(12 \%)$. A possible way for a city to make PeTs available for users at a low cost could be to invest in a system of shared electric scooters.

Interventions could be targeted at improving people's perceptions of PeTs. While safety and cost turned out to be the most problematic aspects of perception, other aspects received relatively low scores as well. This emphasises the importance of improving people's attitudes towards PeTs to encourage their usage as a transport mode in urban areas.

\subsection{Strengths, Limitations and Further Research}

One of the main strengths of this study is the international nature and the size of the data collection. By questioning representative samples of nine cities from four different European countries, the reliability and transferability of the results to other cities are strongly improved. In addition, it allowed identifying differences between cities. A limitation is that the included cities differ from one another on various characteristics, which makes it challenging to identify the causes of the observed effects.

Another strength of this study is that it is, to the best of our knowledge, the first large-scale survey to investigate people's travel behaviour related to the usage of PeTs. In addition, it may be the only large data collection that has been conducted during the short time window where interest in PeTs was growing, and some usage by early adopters started to take off, but before the introduction of shared e-scooter companies in many medium-to-large European cities. As a result, it may be an interesting point of comparison for future research. Future research could conduct similar data collections to monitor how these factors and perceptions evolve over time.

An additional strength is the link that could be made with other modes of active transportation (walking and cycling). Although more research into this link is needed, a noteworthy finding of this study is the significant effect of some psychological determinants of walking and cycling on the PeTs stage of behaviour change.

Given the exploratory nature of this study and the general lack of scientific research around this topic, further research is needed in various (if not all) areas. Future research should further investigate people's motivations and barriers that affect PeT usage. A better insight into the interdependency of PeT usage in combination with, or as a replacement of another transport mode is needed as well. Additionally, since different types of PeTs have rather diverse characteristics, future research could focus on specific types of devices (particularly e-scooters), rather than on the broader group of PeTs included in this study.

Accidents and injuries involving PeTs receive a lot of attention in mass media, but the true extent of the accident risk is unknown [38]. It has been shown that the volume of mass media coverage of a particular type of crash is a poor indicator of its true frequency [39]. Anecdotal evidence suggests that PeTs may have a higher accident risk than other modes 
of active transport [6]. Exploratory research found that $10 \%$ of shared e-scooter users have had an accident and 18\% experienced a near-miss the last time they rode an e-scooter [18]. According to a study performed by the Portland Bureau of Transportation [37], the vast majority of the reported e-scooter injury crashes (84\%) were single-vehicle crashes. This finding is in line with existing research about bicycle crashes, which also suggests that the vast majority of bicycle crashes are single bicycle crashes [40]. These exploratory findings suggest that our participants' concerns related to the safety of PeTs may indeed be justified, although further research into the safety of PeTs is strongly needed.

Author Contributions: Conceptualisation, T.D.C., G.J.W. and E.D.; methodology, T.D.C., E.D. and M.C.; formal analysis, M.C.; investigation, T.D.C., G.J.W., A.F., R.G., D.K., A.C., A.D., and M.C.; data curation, M.C.; writing-original draft preparation, T.D.C. and M.C.; writing-review and editing, T.D.C., G.J.W., A.F., R.G., D.K., A.C., A.D., and M.C.; funding acquisition, T.D.C., G.J.W. and E.D.; and survey preparation and interpretation of results, T.D.C., G.J.W., A.F., R.G., D.K., A.C., A.D., E.D. and M.C. All authors have read and agreed to the published version of the manuscript.

Funding: This research was funded by the European Conference of Directors of Roads (CEDR) Transnational Road Research Programme-Call 2015: User Needs in a Multimodal Context.

Institutional Review Board Statement: Not applicable.

Informed Consent Statement: Informed consent was obtained from all subjects involved in the study.

Data Availability Statement: The data presented in this study are available on request from the corresponding author. The data are not publicly available due to privacy.

Conflicts of Interest: The authors declare no conflict of interest. The funders had no role in the design of the study; in the collection, analyses, or interpretation of data; in the writing of the manuscript, or in the decision to publish the results.

\section{References}

1. Agarwal, A.; Ziemke, D.; Nagel, K. Bicycle superhighway: An environmentally sustainable policy for urban transport. Transp. Res. Part A Policy Pract. 2019, 137, 519-540. [CrossRef]

2. United Nations. World Urbanization Prospects: The 2014 Revision; Department of Economic and Social Affairs, Population Division; United Nations: New York, NY, USA, 2014.

3. Boarnet, M.G.; Giuliano, G.; Hou, Y.; Shin, E.J. First/last mile transit access as an equity planning issue. Transp. Res. Part A Policy Pract. 2017, 103, 296-310. [CrossRef]

4. Bird. A look at E-Scooter Safety-Examining Risks, Reviewing Responsibilities, and Prioritizing Prevention. 2019. Available online: https:/ / www.bird.co/wp-content/uploads/2019/12/Bird-Safety-Report-April-2019.pdf (accessed on 9 March 2021).

5. Krümmel, K.; Gernant, E.; Stolt, R.; Stolze, B.; Moschner, H. Deconstructing the Micromobility Phenomenon-A Strategic Analysis of Crucial Success Factors; Porsche Consulting: Bietigheim-Bissingen, Germany, 2019.

6. Hitchings, J.; Weekley, J.; Beard, G. Review of Current Practice and Safety Implications of Electric Personal Mobility Devices; TRL Limited: Crowthorne, UK, 2019.

7. O’Hern, S.; Estgfaeller, N. A Scientometric Review of Powered Micromobility. Sustainability 2020, 12, 9505. [CrossRef]

8. Hollingsworth, J.; Copeland, B.; Johnson, J.X. Are e-scooters polluters? The environmental impacts of shared dockless electric scooters. Environ. Res. Lett. 2019, 14, 084031. [CrossRef]

9. Smith, C.S.; Schwierterman, J.P. E-Scooter Scenarios: Evaluating the Potential Mobility Benefits of Shared Dockless Scooters in Chicago; Chaddick Institute for Metropolitan Development, DePaul University: Chicago, IL, USA, 2018.

10. Shaheen, S.; Chan, N. Mobility and the Sharing Economy: Potential to Facilitate the First- and Last-Mile Public Transit Connections. Built Environ. 2016, 42, 573-588. [CrossRef]

11. Bai, S.; Jiao, J. Dockless E-scooter usage patterns and urban built Environments: A comparison study of Austin, TX, and Minneapolis, MN. Travel Behav. Soc. 2020, 20, 264-272. [CrossRef]

12. Degele, J.; Gorr, A.; Haas, K.; Kormann, D.; Krauss, S.; Lipinski, P.; Tenbih, M.; Koppenhoefer, C.; Fauser, J.; Hertweck, D. Identifying E-Scooter Sharing Customer Segments Using Clustering. In Proceedings of the 2018 IEEE International Conference on Engineering, Technology and Innovation (ICE/ITMC), Stuttgart, Germany, 17-20 June 2018; pp. 1-8.

13. Caspi, O.; Smart, M.J.; Noland, R.B. Spatial associations of dockless shared e-scooter usage. Transp. Res. Part D Transp. Environ. 2020, 86, 102396. [CrossRef]

14. Almannaa, M.H.; Alsahhaf, F.A.; Ashqar, H.I.; Elhenawy, M.; Masoud, M.; Rakotonirainy, A. Perception Analysis of E-Scooter Riders and Non-Riders in Riyadh, Saudi Arabia: Survey Outputs. Sustainability 2021, 13, 863. [CrossRef]

15. McKenzie, G. Spatiotemporal comparative analysis of scooter-share and bike-share usage patterns in Washington, D.C. J. Transp. Geogr. 2019, 78, 19-28. [CrossRef] 
16. Fitt, H.; Curl, A. E-Scooter Use in New Zealand: Insights around Some Frequently Askede Questions; University of Canterbury: Christchurch, New Zealand, 2019; Available online: https:/ /ir.canterbury.ac.nz/handle/10092/16336 (accessed on 9 March 2021).

17. James, O.; Swiderski, J.I.; Hicks, J.; Teoman, D.; Buehler, R. Pedestrians and E-Scooters: An Initial Look at E-Scooter Parking and Perceptions by Riders and Non-Riders. Sustainability 2019, 11, 5591. [CrossRef]

18. Berge, S.H. Kickstart for Mikromobilitet-En pilotstudie om Elsparkesykler; TØI Institute of Transport Economics: Oslo, Norway, 2019. (In Norwegian)

19. Bamberg, S. Is a Stage Model a Useful Approach to Explain Car Drivers' Willingness to Use Public Transportation? J. Appl. Soc. Psychol. 2007, 37, 1757-1783. [CrossRef]

20. Prochaska, J.O.; Velicer, W.F. The Transtheoretical Model of Health Behavior Change. Am. J. Health Promot. 1997, 12, 38-48. [CrossRef] [PubMed]

21. Dunlap, R.E.; Liere, K.D.V.; Mertig, A.G.; Jones, R.E. New Trends in Measuring Environmental Attitudes: Measuring Endorsement of the New Ecological Paradigm: A Revised NEP Scale. J. Soc. Issues 2000, 56, 425-442. [CrossRef]

22. Cools, M.; Brijs, K.; Tormans, H.; Moons, E.; Janssens, D.; Wets, G. The socio-cognitive links between road pricing acceptability and changes in travel-behavior. Transp. Res. Part A Policy Pract. 2011, 45, 779-788. [CrossRef]

23. Cools, M.; Declercq, K.; Janssens, D.; Wets, G. Onderzoek Verplaatsingsgedrag Vlaanderen 4.2 (2009-2010); Transportation Research Institute, Hasselt University: Hasselt, Belgium, 2011.

24. Kutner, M.H.; Nachtsheim, C.J.; Neter, J.; Li, W. Applied Linear Statistical Models, 5th ed.; Mc Graw Hill India: Nodia, India, 2013, ISBN 978-1-259-06474-6.

25. Verplanken, B.; Wood, W. Interventions to Break and Create Consumer Habits. J. Public Policy Mark. 2006, 25, 90-103. [CrossRef]

26. Bieliński, T.; Ważna, A. Electric Scooter Sharing and Bike Sharing User Behaviour and Characteristics. Sustainability 2020, 12, 9640. [CrossRef]

27. Abay, K.A.; Mannering, F.L. An empirical analysis of risk-taking in car driving and other aspects of life. Accid. Anal. Prev. 2016, 97, 57-68. [CrossRef]

28. De Ceunynck, T.; Daniels, S.; Vanderspikken, B.; Brijs, K.; Hermans, E.; Brijs, T.; Wets, G. Is there a spillover effect of a right turn on red permission for bicyclists? Transp. Res. Part F Traffic Psychol. Behav. 2016, 36, 35-45. [CrossRef]

29. Palamara, P.; Molnar, L.; Eby, D.; Kopinanthan, C.; Langford, J.; Gorman, J.; Broughton, M. Review of Young Driver Risk Taking and Its Association with other Risk Taking Behaviours; Curtin-Monash Accident Research Centre: Bentley, Australia; Michigan Center for Advancing Safe Transportation throughout the Lifespan: Ann Arbor, MI, USA, 2012.

30. Boniface, K.; McKay, M.P.; Lucas, R.; Shaffer, A.; Sikka, N. Serious Injuries Related to the Segway ${ }^{\circledR}$ Personal Transporter: A Case Series. Ann. Emerg. Med. 2011, 57, 370-374. [CrossRef]

31. Xu, J.; Shang, S.; Qi, H.; Yu, G.; Wang, Y.; Chen, P. Simulative investigation on head injuries of electric self-balancing scooter riders subject to ground impact. Accid. Anal. Prev. 2016, 89, 128-141. [CrossRef] [PubMed]

32. Xu, J.; Shang, S.; Yu, G.; Qi, H.; Wang, Y.; Xu, S. Are electric self-balancing scooters safe in vehicle crash accidents? Accid. Anal. Prev. 2016, 87, 102-116. [CrossRef] [PubMed]

33. De Ceunynck, T.; Slootmans, F.; Daniels, S. Characteristics and profiles of moped crashes in urban areas: An in-depth study. Transp. Res. Rec. 2018, 2672, 85-95. [CrossRef]

34. Tuncer, S.; Laurier, E.; Brown, B.; Licoppe, C. Notes on the practices and appearances of e-scooter users in public space. J. Transp. Geogr. 2020, 85, 102702. [CrossRef]

35. Scheepers, C.E.; Wendel-Vos, G.C.W.; den Broeder, J.M.; van Kempen, E.E.M.M.; van Wesemael, P.J.V.; Schuit, A.J. Shifting from car to active transport: A systematic review of the effectiveness of interventions. Transp. Res. Part A Policy Pract. 2014, 70, 264-280. [CrossRef]

36. Krier, C.; Chrétien, J.; Louvet, N. Usages et Usagers de Services de Trottinettes Electriques en Free-Floating en France; 6t: Paris, France, 2019. (In French)

37. Portland Bureau of Transportation. 2018 E-Scooter Findings Report; Portland Bureau of Transportation: Portland, OR, USA, 2019.

38. Yang, H.; Ma, Q.; Wang, Z.; Cai, Q.; Xie, K.; Yang, D. Safety of micro-mobility: Analysis of E-Scooter crashes by mining news reports. Accid. Anal. Prev. 2020, 143, 105608. [CrossRef] [PubMed]

39. De Ceunynck, T.; De Smedt, J.; Daniels, S.; Wouters, R.; Baets, M. “Crashing the gates"—Selection criteria for television news reporting of traffic crashes. Accid. Anal. Prev. 2015, 80, 142-152. [CrossRef]

40. Schepers, P.; Agerholm, N.; Amoros, E.; Benington, R.; Bjørnskau, T.; Dhondt, S.; de Geus, B.; Hagemeister, C.; Loo, B.P.Y.; Niska, A. An international review of the frequency of single-bicycle crashes (SBCs) and their relation to bicycle modal share. Inj. Prev. 2014, 21, e138-e143. [CrossRef] [PubMed] 